\title{
Book Review: The Oxford Handbook of Conflict Management in Organizations
}

Edited by William K. Roche, Paul Teague, and Alexander J.S. Colvin, Oxford, UK: Oxford University Press, 2014

Jennifer Hennessy*

School of Business, Waterford Institute of Technology, Ireland

This book offers a multidimensional review on conflict management including theoretical perspectives, approaches to conflict management, exemplars and innovators in the area and international developments in the field. Roche, Teague and Colvin provide a comprehensive introduction to developments in conflict management, which set the scene for the rest of the text. In each of the sections which follow, their introduction weaves the various chapter themes together to provide a sense of cohesion and logic to what is often an unwieldy range of topics within the subject area.

Part one notes in the introduction how conflict management and dispute resolution has been an undertheorised area and draws from a wide domain to explore theoretical perspectives in the field while also raising the question of how we wish to think about the 'implications of conflict and its management and resolution within organisations' (p. 8). Chapter one challenges the goals and assumptions that underpin views of conflict management in organisations. Chapter two asks questions of labour-management conflict, where does it come from, why it varies and what it means for conflict management systems? Chapter three focuses on employment rights and workplace conflict from a governance perspective, and finally in this part of the text, chapter four highlights the relationship between HRM and conflict management, focusing specifically on employee voice mechanisms.

Part two examines the various approaches that organisations can adopt to conflict management, from both an individual and collective perspective. This section is particularly rich in content, providing a multilevel analysis of conflict in organisations, while also exploring both traditional and alternative forms of conflict management. Chapter five deals with collective bargaining and grievance procedures, with chapter nine also focused on grievance procedures, but from the specific perspective of non-unionised environments. In chapter six, there is an examination of third-party processes in employment disputes and chapter seven systematically deals with interestbased bargaining. Chapter eight looks at the burgeoning area of workplace mediation. Chapter 10 focuses on the unique role of the organisational ombudsman in dealing with conflict. The trend in the 1990s to devolve HRM practices to the front-line manager is covered in chapter 11 and this practice is critically discussed in the context of workplace conflict. Chapter 12 concludes part two by providing a thorough discussion of the existing research on conflict management systems.

Part three provides case studies, which illustrate some of the topics discussed in previous chapters. These include the role of mediation in the US postal service and the lessons learnt from the process; a contextual and comprehensive exploration of the evolution of a labour-management partnership in Kaiser Permanente; the complexities of providing a mediation and arbitration service in the New Zealand Police Service and finally experiences of judicial mediation in employment tribunals within the UK which asks the question at the end of the chapter as to how judicial mediation should best be approached.

In part four, we are offered a global perspective on conflict resolution with viewpoints from Europe (Germany and the UK), the US, China, Japan, Australia and New Zealand. As noted by the editors in the introduction to this part 
of the text the chapters illustrate similarities between the countries regarding developments in conflict management 'yet exhibit contrasting features with regard to how workplace conflict is governed' (p. 354).

The above review does not focus so much on providing a critique of the text, but instead uses the opportunity to introduce the diverse yet inclusive range of topics addressed within this tome. From the brief introduction to the content, it is evident that the text is relevant to academics well versed in the field of conflict management, and those who are only beginning to dip their toes in the water! That is not to say that the practitioner is ignored, with the content being relevant to those wishing to stay abreast of developments in theory and practice within the area. The editors suggest that 'up to now no authoritative international review has been available to inform professional practice or synthesise academic knowledge' (p.2), this book convincing fills that void, as it confidently addresses the various facets of the conflict management literature. 